\title{
Effects Of a Ceiling Diffuser On Diffuse Ceiling Ventilation (DCV) Performance
}

\author{
Alessandro Nocente ${ }^{1,2, *}$, Tufan Arslan ${ }^{1}$, Steinar Grynning ${ }^{2}$, Francesco Goia ${ }^{1}$ \\ ${ }^{1}$ Norwegian University of Science and Technology (NTNU), Trondheim, Norway \\ ${ }^{2}$ SINTEF Building and Infrastructure, Trondheim, Norway \\ *Corresponding author: alessandro.nocente@ntnu.no
}

\begin{abstract}
Diffuse Ceiling Ventilation (DCV) is a promising concept to address the internal comfort requirements in modern buildings. Among various possible configuration, the use of sound absorbing perforated panels is the most attractive since it does not require substantial modification in the design of the suspended ceilings normally present in office room. Numerical simulations are a valuable tool to evaluate the performance of a DCV avoiding the cost of an experimental campaign. As today, all the numerical studies are usually carried out by modeling the perforated ceiling as a porous medium, focusing more on its general performance than on the optimisation of the diffuser design. In a previous study by the authors, a CFD model was used to optimise the size and distribution of the dropped ceiling perforation in a room section, modeling the actual perforation of panels. This paper presents the results of simulations carried out using of a full scale numerical model of an office room with DCV with focus on the performance comparison between a continuous and non-continuous ceiling diffuser surface. The results show that the noncontinuous diffuser design does not affect the internal comfort. The air velocity distribution in the room is far below the discomfort limit. In addition, the noncontinuous system does not introduce a significant increase in the total pressure loss of the ventilation system.
\end{abstract}

\section{Introduction}

Diffuse Ceiling Ventilation (DCV) is a novel concept for ventilation in low and plus energy buildings. The system uses the space between the ceiling slabs and the suspended ceiling as a plenum for ventilation air. The fresh air is then distributed in the room trough the dropped ceiling which acts as an air diffuser. In office buildings is common to have a suspended ceiling made of sound-absorbing perforated panels. These panels, because of their own characteristics, are suitable to be used as air diffusers without modifications. Previous researches demonstrated that DCV presents several advantages compared to traditional duct based ventilation. Due to the larger diffuser area, a higher amount of ventilation air can be dis- tributed with a low velocity and this reduces the pressure drop in the system while contributing to increase the internal comfort by avoiding drafts. In addition this solution has a lower investment cost than traditional ventilation systems Zhang et al. (2016). In one of the first studies the DCV was presented by Van Wagenberg and Smolders (2002) as a solution to provide sufficient ventilation air in livestock buildings. Jacobs et al. (2008) applied DCV to schools as a retrofitting solution for air quality improvement and demonstrated a demonstrated in indoor air quality and thermal comfort. Experimental evaluations of DCV performances were conducted in a test chamber by Petersen et al. (2014) and Fan et al. (2013), the latter using a more detailed office room layout. In Hviid and Svendsen (2013) the authors tested a full scale ceiling in a climatic chamber using two different porous surfaces. The results showed an air change efficiency equal to fully mixed conditions, excluded any evidence of thermal discomfort and demonstrated a very low pressure drop but still sufficient to support the internal pressure of the plenum and ensure an uni-directional air flow. The presence of a large volume in the plenum makes this solution attractive for coupling diverse air treatment systems with the ventilation, as for example heating and cooling. Zhang et al. (2015) presented the results of an experimental campaign in a hot-box facility of a DCV coupled with a water-based heating system in the ceiling slabs.

Experimental campaign of this kind are expensive and time consuming, therefore the use of computer simulation is largely beneficial, at least for the preliminary design of the systems. Numerical simulation to evaluate the performance of DCV were used by Mikeska and Fan (2015) and Zhang et al. (2017). In these and similar studies the dropped ceiling is usually modeled using the porous medium model. One of the limitations commonly associated with the use of DCV is the uneven velocity profile of the air leaving the ceiling perforation. In fact the injection of air in the plenum takes place either in a single point such a duct, or, when the DCV is coupled with natural ventilation from an external wall, through one of the vertical surfaces of the plenum. In both cases the air velocity in the plenum tends to decrease with 
the distance from the injection point both for friction and for the decrease in flow rate due to air already injected through the diffuser. A proper design of the suspended ceiling can partially solve this problem by selectively introducing a different pressure drop. In previous works, the authors modeled the diffuser as an actual perforated surface starting from three models of sound-absorbing panels present on the market. Using a slice of the plenum as computational domain, a series of panel distributions were simulated and for each distribution the velocity profile at the outlet was evaluated, Nocente et al. (2018). The result brought to the identification of an optimal panel combination for the considered room, this was used to build up a larger numerical domain (a slice of the whole room) and the internal flow was studied. The analysis of the results showed the absence of discomfort due to drafts and the delivery of an adequate amount of ventilation air. A more comprehensive study of the "room slice" domain was repeated in Nocente et al. (2018). Here the isothermal hypothesis was removed to investigate the effects on the thermal comfort in case of natural ventilation with varying outdoor temperature conditions. The solution presented a good impact on the comfort conditions in a quite large interval of outdoor temperature. For extreme winter and summer conditions, the authors investigated in a theoretical way the effect that a ceiling integrated conditioning system could have on the internal comfort. The results were promising for what concerned heating in winter, while it presented more problems such as thermal stratification in summer conditions and the necessity of further investigations. The present work compares the performance of a continuous and a non-continuous (chessboard) ceiling panel distribution (Figure 1) in a full scale numerical model of a typical office room. As mentioned, the low pressure drop introduced by this ventilation system is one of the advantages, particularly important when natural ventilation is used. A chessboard distribution may have a positive effect, in fact the flow leaving the perforation will face a lower resistance, and the energy saving can overcome the additional losses caused by a higher air velocity in the perforation.

\section{Methods}

\section{Computational Domain}

The computational domain (Figure 2) is constituted by a room with dimension ( $\mathrm{W} \times \mathrm{L} \times \mathrm{H}) 3.6 \mathrm{~m} \times 3.6 \mathrm{~m}$ $\mathrm{x} 3 \mathrm{~m}$, and a plenum with the same horizontal area and a height of $0.35 \mathrm{~m}$. The air is injected in the plenum via the whole vertical plenum surface, this surface is ideally facing the outer wall.

Two outlets were alternatively considered for the calculation and the two domain are here referred to as configuration Outlet 1 and Outlet 2. In configuration Outlet 1 the domain outlet represents an extraction duct and it is modeled as a square opening with di-

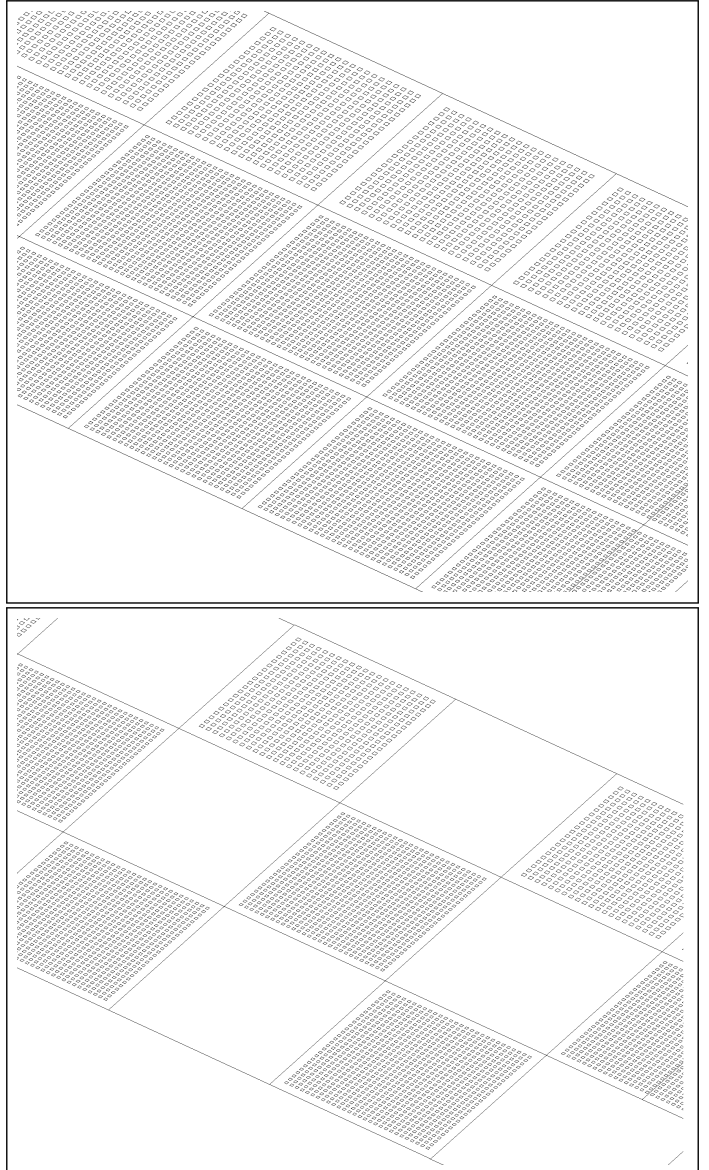

Figure 1: Example of full ceiling panel distribution (above) and chessboard distribution (below).

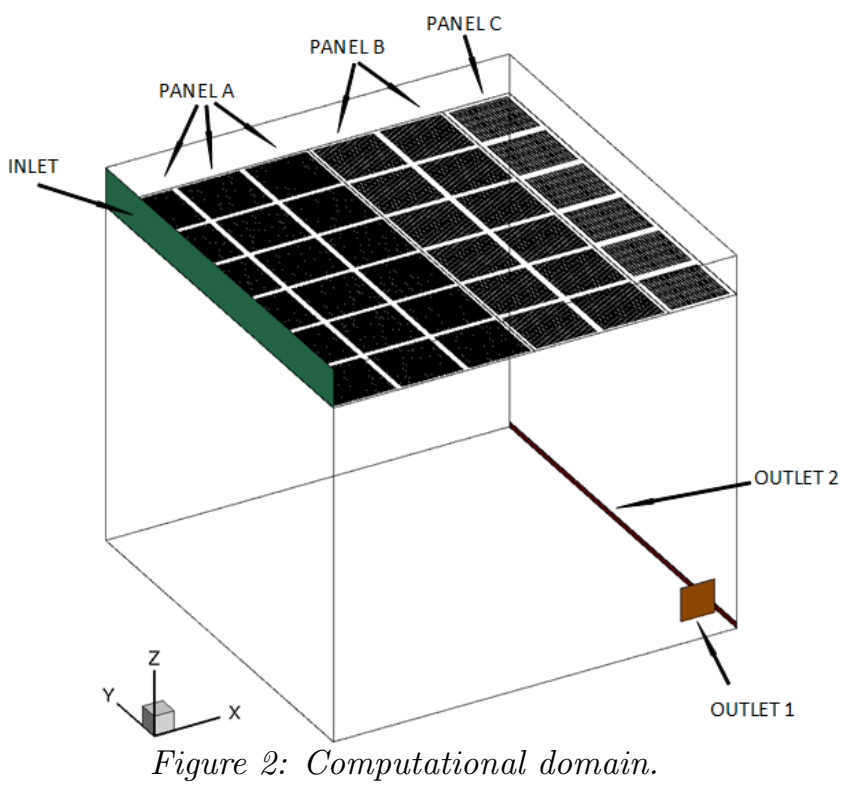

mensions $0.3 \mathrm{~m} \times 0.3 \mathrm{~m}$ located on one of the side walls (i.e. normal to the surface where the plenum inlet is). Configuration Outlet 2 sees the outlet located at the bottom of the wall opposite to the inlet plane (i.e. the plane ideally containing the door. It is modeled as an opening with $5 \mathrm{~cm}$ height along 
the whole wall on the opposite side of the inlet. The plenum and the room are separated by a dropped ceiling composed of three different panels designed on the characteristics of sound-absorbing perforated panels available on the market. All panels have dimensions $600 \mathrm{~mm} \times 600 \mathrm{~mm}$. The perforation dimension and the perforation rate is reported in Table $1 . \quad$ The

Table 1: Perforation dimension and rate of the panels Nocente et al. (2018).

\begin{tabular}{|c|c|c|}
\hline Panel & Holes $\left[\mathrm{mm}^{2}\right]$ & $\begin{array}{c}\text { Perforation } \\
\text { Rate }[\%]\end{array}$ \\
\hline Panel A & $3 \times 3$ & 11 \\
\hline Panel B & $9 \times 9$ & 18 \\
\hline Panel C & $12 \times 12$ & 18 \\
\hline
\end{tabular}

panel distribution follows the result of the calculations in Nocente et al. (2018) for a room section with the same length, and the sequence, starting from the inlet side, is 3 type A, 2 type B and 1 type C. This distribution have demonstrated to be able to balance to a certain extent the air velocity unevenness at the dropped ceiling, with a slight increase of velocity in the central part of the room. The non-continuous case considered in this work was designed by replacing every second panel with a non-perforated surface, alternatively for each row realising a chessboard distribution.

\section{Numerical Model}

The computational mesh counts approximately 120 million mixed cells (polyhedral and cartesian). The high resolution of the mesh is required to ensure the presence of a sufficient amount of cells in each panel hole to perform a satisfactory calculation. All the simulations were realised using the code ANSYS FLUENT. A second order upwind spatial discretisation was used along with the SIMPLE algorithm for the pressure-velocity coupling. The turbulence was calculated with a standard k- $\varepsilon$ turbulence model. The $\mathrm{k}-\varepsilon$ model is the most widely used and validated turbulence model to simulate mean flow characteristics for the flow conditions with applications ranging from industrial to environmental flows and it has been highly popular for inner flows. The standard variant of $\mathrm{k}-\varepsilon$ is used for simplicity and basic requirement of initial and boundary conditions of turbulent quantities. The complexity of the model in terms of dimensions, perforation and high density mesh require a considerable computational effort. The simulations ran in the supercomputer Vilje Vilje (Vilje) hosted by NTNU, using a total of 256 cores (16 nodes) and required around 300 GB RAM. The simulations were conducted in transient state, assuming a time step $\Delta t=0.05 \mathrm{~s}$ and 1000 steps. The calculation wall time was around $24 \mathrm{hrs}$. The boundary conditions imposed to the model are inlet velocity and a constant outlet pressure. The velocity at the inlet of the plenum is constant and it is calculated to provide a ventilation air flow of $2.4 \mathrm{~m}^{3} / \mathrm{h}$ per square meter of room floor area. The outlet was set to atmospheric pressure. All the calculation are isothermal since the study focuses on the fluid-mechanic problem without considering effects induced by different air density. A constant density, corresponding to air at $20^{\circ} \mathrm{C}$ was used.

\section{Results}

The results presented are the average of all the variables values over all the time steps of the transient state simulations. Velocities, flow rates and pressure overviews are reported in Table 2 and Table 3. Each of the tables shows the results for the continuous and chessboard distribution for the two outlet geometries (Outlet 1 and Outlet 2). The average velocity

Table 2: Calculated quantities in the continuous and chessboard distributions for outlet configuration 1 .

\begin{tabular}{|c|c|c|c|}
\hline \multicolumn{4}{|c|}{ CONFIGURATION OUTLET 1} \\
\hline \multicolumn{4}{|c|}{ Continuous Distribution } \\
\hline Panels & $\mathrm{A}$ & $\mathrm{B}$ & $\mathrm{C}$ \\
\hline $\begin{array}{c}\text { Avg z velocity } \\
{[\mathrm{m} / \mathrm{s}]}\end{array}$ & 0.0025 & 0.0064 & 0.0077 \\
\hline $\begin{array}{l}\text { Mass flow rate } \\
\text { (full surface } \\
\text { avg) }[\mathrm{kg} / \mathrm{s}]\end{array}$ & 0.0023 & 0.006 & 0.0037 \\
\hline $\begin{array}{l}\text { Pressure drop } \\
\qquad[P a]\end{array}$ & \multicolumn{3}{|c|}{0.01} \\
\hline $\begin{array}{c}\text { Max velocity } \\
{[\mathrm{m} / \mathrm{s}]}\end{array}$ & \multicolumn{3}{|c|}{0.13 (at the outlet) } \\
\hline \multicolumn{4}{|c|}{ CONFIGURATION OUTLET 1} \\
\hline \multicolumn{4}{|c|}{ Chessboard Distribution } \\
\hline Panels & $\mathrm{A}$ & $\mathrm{B}$ & $\mathrm{C}$ \\
\hline $\begin{array}{c}\text { Average } \mathrm{z} \\
\text { velocity }[\mathrm{m} / \mathrm{s}]\end{array}$ & 0.0059 & 0.0013 & 0.0014 \\
\hline $\begin{array}{c}\text { Mass flow rate } \\
\text { (full surface } \\
\text { avg) }[\mathrm{kg} / \mathrm{s}]\end{array}$ & 0.026 & 0.0059 & 0.0033 \\
\hline $\begin{array}{l}\text { Pressure drop } \\
{[P a]}\end{array}$ & \multicolumn{3}{|c|}{0.01} \\
\hline $\begin{array}{l}\text { Max velocity } \\
{[\mathrm{m} / \mathrm{s}]}\end{array}$ & \multicolumn{3}{|c|}{0.13 (at the outlet) } \\
\hline
\end{tabular}

reported represents the average of the components along the z-axis of the velocity of the air leaving the perforation calculated for all the panels of the same type included in the ceiling configuration. The mass flow rate is, instead, reported as averaged along the whole area of the ceiling section containing a certain type of panels (i.e. the same area in the continuous and the chessboard case, including the non perforated panels in the latter). This representation was chosen to due to the different perforation rates of the panels, and to give a more direct idea of how the air velocity out of the diffuser increases while keeping constant the amount of ventilation air injected. The pressure drop represent the losses in the whole system and it 
Table 3: Calculated quantities in the continuous and chessboard distributions for outlet configuration 2.

\begin{tabular}{|c|c|c|c|}
\hline \multicolumn{4}{|c|}{ CONFIGURATION OUTLET 2} \\
\hline \multicolumn{4}{|c|}{ Continuous Distribution } \\
\hline Panels & $\mathrm{A}$ & $\mathrm{B}$ & $\mathrm{C}$ \\
\hline $\begin{array}{c}\text { Avg z velocity } \\
{[m / s]}\end{array}$ & 0.0025 & 0.0064 & 0.0077 \\
\hline $\begin{array}{l}\text { Mass flow rate } \\
\text { (full surface } \\
\text { avg) }[\mathrm{kg} / \mathrm{s}]\end{array}$ & 0.0022 & 0.006 & 0.0036 \\
\hline $\begin{array}{c}\text { Pressure drop } \\
{[P a]}\end{array}$ & \multicolumn{3}{|c|}{0.0034} \\
\hline $\begin{array}{c}\text { Max velocity } \\
{[\mathrm{m} / \mathrm{s}]}\end{array}$ & \multicolumn{3}{|c|}{0.063 (at the outlet) } \\
\hline \multicolumn{4}{|c|}{ CONFIGURATION OUTLET 2} \\
\hline \multicolumn{4}{|c|}{ Chessboard Distribution } \\
\hline Panels & $\mathrm{A}$ & $\mathrm{B}$ & $\mathrm{C}$ \\
\hline $\begin{array}{c}\text { Average } \mathrm{z} \\
\text { velocity }[\mathrm{m} / \mathrm{s}]\end{array}$ & 0.0059 & 0.0013 & 0.0014 \\
\hline $\begin{array}{c}\text { Mass flow rate } \\
\text { (full surface } \\
\text { avg) }[\mathrm{kg} / \mathrm{s}]\end{array}$ & 0.026 & 0.0059 & 0.0033 \\
\hline $\begin{array}{c}\text { Pressure drop } \\
{[P a]}\end{array}$ & \multicolumn{3}{|c|}{0.0034} \\
\hline $\begin{array}{l}\text { Max velocity } \\
{[\mathrm{m} / \mathrm{s}]}\end{array}$ & \multicolumn{3}{|c|}{0.063 (at the outlet) } \\
\hline
\end{tabular}

is calculated between the inlet and the outlet. In all cases, the maximum air velocity calculated in the whole volume is low and concentrated in the immediate surroundings of the outlet in configuration Outlet 1 .

Figures 3 to 6 show the velocity contours on three horizontal planes in the room and the more detailed contour of the top plane for the continuous and chessboard distribution in the two configuration. The planes chosen for this representation are the room horizontal mid plane (centre of the room height), the horizontal plane cutting the outlet in configuration Outlet 1 (bottom) and the horizontal plane located 4 $\mathrm{cm}$ below the surface of the suspended ceiling (top). The latter was chosen in order to show a fully developed flow leaving the ceiling perforation. The same plane is shown in the figures with more contour levels to better report the velocity distribution at the diffuser.

\section{Discussion}

The results reported in Table 2 and Table 3 show a higher velocity magnitude at the outlet of the perforated panels when the chessboard configuration is adopted in both configuration. This was largely expected as well the roughly doubled velocity magnitude. The pressure drop introduced by the DCV is low in both configurations. What it is interesting to underline is that a reduction of approximately two thirds in the pressure drop is observed between configuration Outlet 1 and Outlet 2, while no substantial difference is visible in each configuration between the continuous and the chessboard ceiling. Hence, not only the choice of the outlet influenced to a higher extent the pressure drop, but the different panel distribution seems not to be influencing this parameter. The maximum air velocity that is observed in the whole room volume is below the discomfort limit in the configuration Outlet 2 while it is higher than 0.1 $\mathrm{m} / \mathrm{s}$ in a small volume in configuration Outlet 1 ISO 7730:2005 (2010). In both configurations there is no difference continuous and chessboard configuration, and the higher velocity is always locate in the immediate surroundings of the outlet. The ceiling contours (right) in Figures 3-6 reveals the velocity distribution at the ceiling outlet. The results are in line with Nocente et al. (2018) with small difference probably due to the larger computational domain. The chessboard configuration shows a general increase in velocity in all panels, as expected, but does not show substantial differences between the two outlet configuration. This suggests that the choice of the outlet does not influence the performance of the DCV, but also that the DCV does not influence the internal air circulation in the room. The latter seems, instead, more influenced by the choice of the outlet geometry. In in the mid plane of Figures 5 and 6, in fact, a general lower velocity is observable. In particular in Figure 6 it is possible to identify three zones with higher velocity on the mid plane otherwise not visible in Figure 4. This means that the jets originated from the first row of panels arrive undisturbed in the middle of the room. The very low velocity of this zones, anyway, does not represent any problem for the internal comfort.

\section{Conclusions}

The results of the full-scale simulations presented in this paper, show that the DCV has a positive impact on the internal comfort conditions of a typical office room. It delivers sufficient amount of ventilation air ensuring the absence of draft and working with a low pressure drop along the whole system. The comparison between the full ceiling and the chessboard distribution shows that, although the total diffuser area is halved, thus doubling the velocity of the air leaving the diffuser, this does not translate into a significant increase in the air velocity inside the room. In both cases the air velocity is below the discomfort limit with an increase of almost one order of magnitude in the outlet area. Two different outlet configurations were simulated and the results showed that the influence of the outlet choice on the performance of the DCV is negligible. The chessboard panel distribution, despite increasing the air velocity, did not show any influence on the dynamic performance of the ventilation system in terms of pressure drop. It was instead 

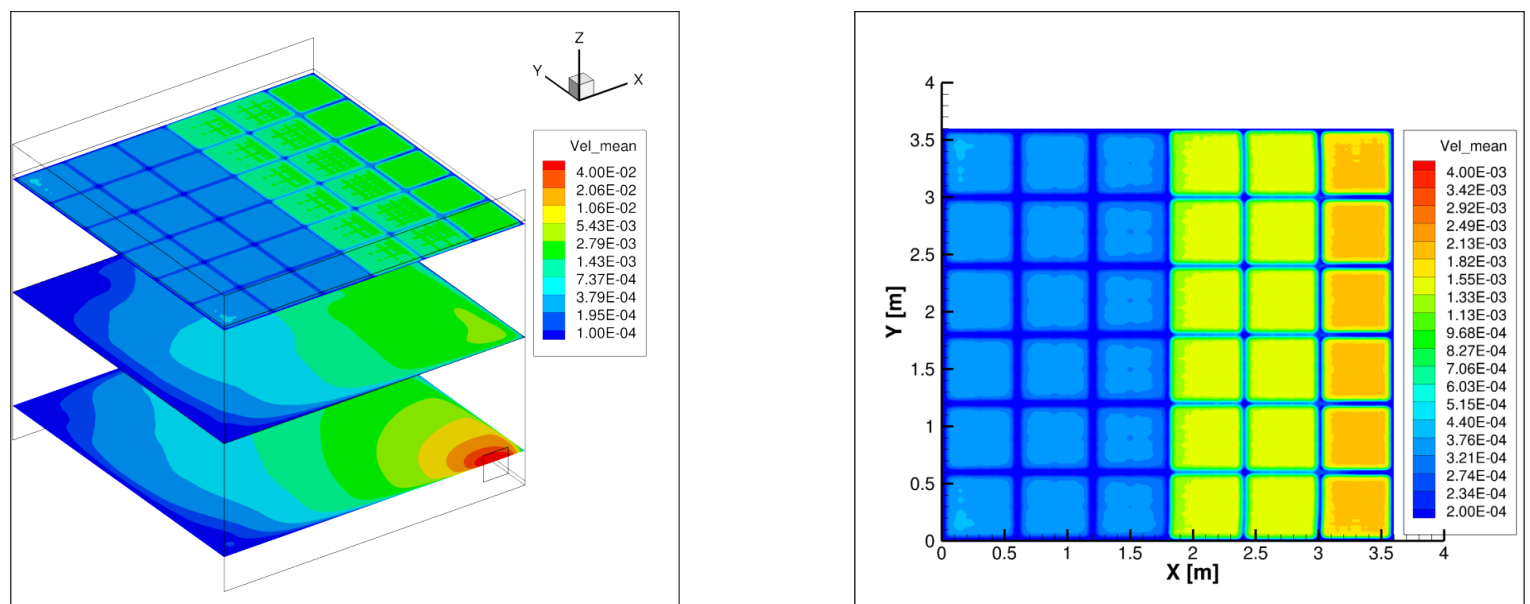

Figure 3: Velocity contour: 3 horizontal planes(left), the top plane below the ceiling (right) for the continuous distribution in configuration Outlet 1.
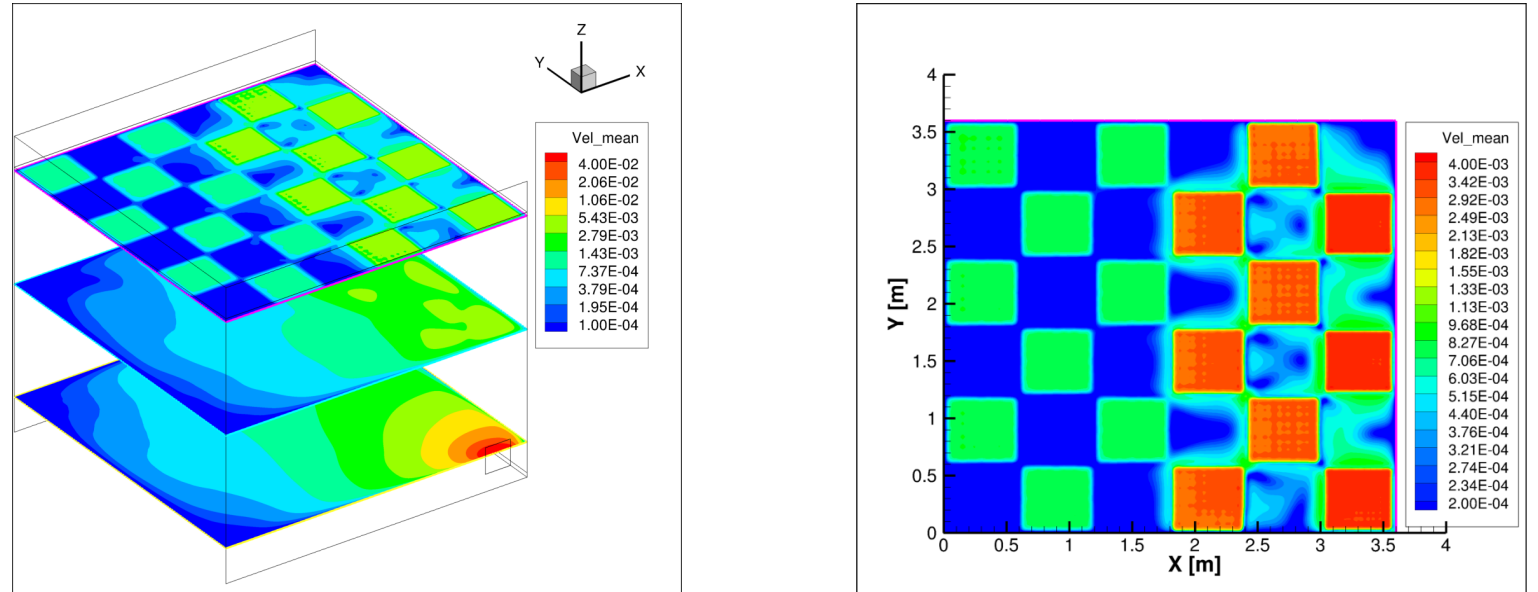

Figure 4: Velocity contour: 3 horizontal planes(left), the top plane below the ceiling (right) for the chessboard distribution in configuration Outlet 1.
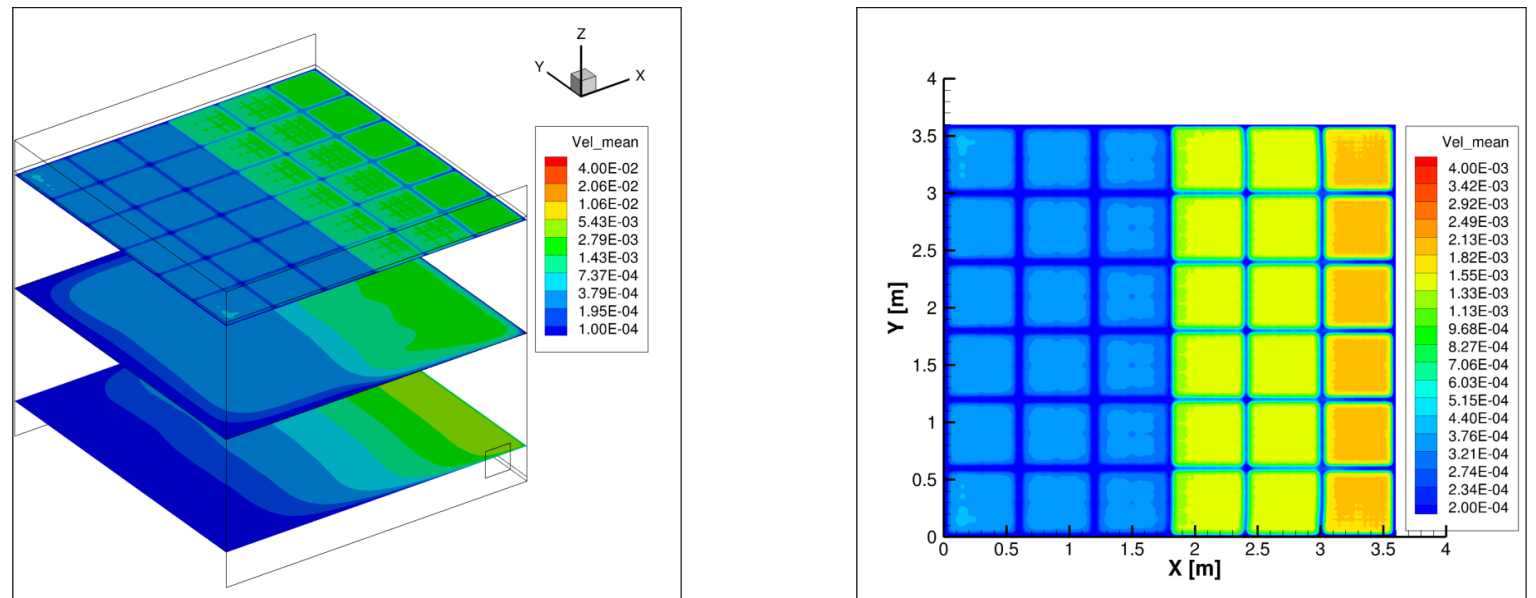

Figure 5: Velocity contour: 3 horizontal planes(left), the top plane below the ceiling (right) for the chessboard distribution in configuration Outlet 2. 

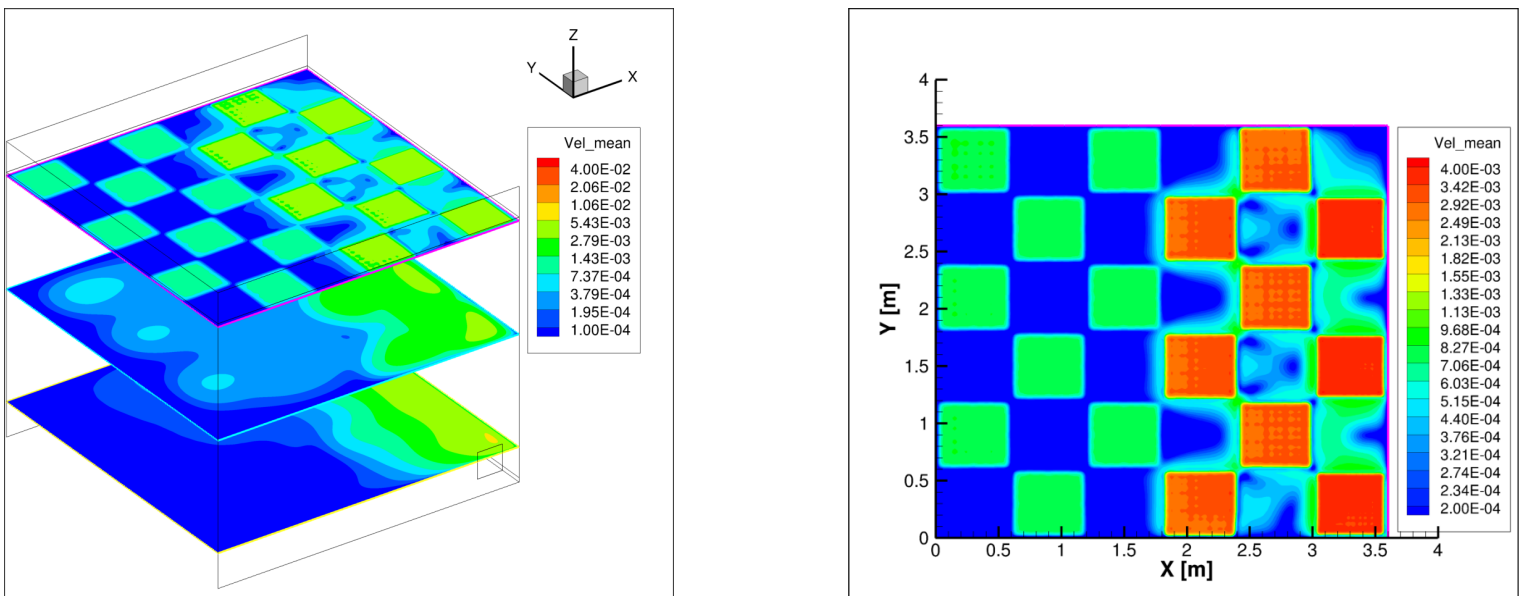

Figure 6: Velocity contour: 3 horizontal planes(left), the top plane below the ceiling (right) for the chessboard distribution in configuration Outlet 2.

observed a more marked influence of the outlet choice. The present calculations suggest a beneficial effect of the chessboard distribution. The phenomenon behind this beneficial influence could be related to a positive entrainment effect favoured by the air jets leaving the ceiling diffuser. In any case further investigation is necessary to evaluate and give an estimate of this effect. In addition, a series of new simulation will be carried out, removing the isothermal hypothesis at the inlet and investigating the effect of the outdoor temperature on the internal comfort when natural ventilation is used with air injection directly from the the external wall. The use of CFD simulation to evaluate the efficiency and the performance of DCV is a very valuable tool in the design of these systems. Despite the large computational effort associated with the use of the presented model, the numerical investigation still represent an economical alternative to the experimental verifications on a physically built system. Furthermore, it can reveal the occurrence of phenomena that, at first sight, might be not trivial. The evaluation of an eventual change in the soundabsorbing properties of this kind of panels when used as air diffuser is not the object of this paper. A series of experimental measurements on this will be a valuable research result. An experimental campaign involving tracer gas and pressure difference measurements on DCV is being performed at the moment. The results will contribute to the validation and the eventual tuning of the computational model.

\section{Acknowledgments}

This work has been supported by the Research Council of Norway and several partners through the project "Advanced facades with integrated technology - SkinTech" (nr. 255252).

The authors wish to thank Uninett/Sigma for the support and the computing time.

\section{References}

Fan, J., C. Hviid, and H. Yang (2013). Performance analysis of a new design of office diffuse ceiling ventilation system. Energy and Buildings 59, 73-81.

Hviid, C. A. and S. Svendsen (2013). Experimental study of perforated suspended ceilings as diffuse ventilation air inlets. Energy and Buildings 56, 160 -168 .

ISO 7730:2005 (2010). Ergonomics of the thermal environment - analytical determination and interpretation of thermal comfort using calculation of the pmv and ppd indices and local thermal comfort criteria.

Jacobs, P., E. C. van Oeffelen, and B. Knoll (2008). Diffuse ceiling ventilation, a new concept for healthy and productive classrooms. Volume 3.

Mikeska, T. and J. Fan (2015). Full scale measurements and CFD simulations of diffuse ceiling inlet for ventilation and cooling of densely occupied rooms. Energy and Buildings 107, 59-67.

Nocente, A., F. Goia, and S. Grynning (2018). Numerical investigation of a diffuse ventilation ceiling system for buildings with natural and hybrid ventilation. In Proceedings of the 7th International Building Physics Conference, 23.09.2018 26.09.2018, Syracuse, USA, pp. 859-864.

Nocente, A., S. Grynning, H. M. Mathisen, and F. Goia (2018). Computational fluid dynamics study of a diffuse ceiling ventilation system through perforated sound absorbing ceiling panels. In Proceedings of Roomvent $\&$ Ventilation 2018, Espoo, Finland 2-5 June, pp. 899-904.

Petersen, S., N. Christensen, C. Heinsen, and A. Hansen (2014). Investigation of the displacement effect of a diffuse ceiling ventilation system. Energy and Buildings 85, 265-274. 
Van Wagenberg, A. v. and M. Smolders (2002). Contaminant and heat removal effectiveness of three ventilation systems in nursery rooms for pigs. Transactions of the ASAE 45(6), 1985.

Vilje. https://www.hpc.ntnu.no/display/hpc/Vilje.

Zhang, C., P. Heiselberg, Q. Chen, and M. Pomianowski (2017). Numerical analysis of diffuse ceiling ventilation and its integration with a radiant ceiling system. Building Simulation 10(2), 203218.

Zhang, C., P. K. Heiselberg, M. Pomianowski, T. Yu, and R. L. Jensen (2015). Experimental study of diffuse ceiling ventilation coupled with a thermally activated building construction in an office room. Energy and Buildings 105, $60-70$.

Zhang, C., T. Yu, P. K. Heiselberg, M. Z. Pomianowski, and P. V. Nielsen (2016). Diffuse ceiling ventilation-design guide. 